\title{
Turismo religioso e cultural na Amazônia: a turistificação do espaço no Círio de Nazaré em Belém (Pará-PA, Brasil)
}

\section{Religious and cultural tourism in Amazon Region: the space touristification at Círio de Nazaré in Belém (Pará-PA, Brazil)}

\author{
Débora Rodrigues de Oliveira Serra (SERRA, D. R. de O.)
}

\begin{abstract}
RESUMO - No presente artigo se aborda o Círio de Nazaré em Belém (Pará-PA, Brasil), uma das metrópoles da região amazônica, buscando sua relação com as práticas turísticas encontradas nesse complexo de eventos. A pesquisa se deu entre os anos de 2012 a 2014, complementando-se com a atualização de dados oficiais em 2015. A metodologia utilizada constituiu-se de levantamento bibliográfico acerca da festividade do Círio de Nazaré, do espaço geográfico e sua apropriação para o turismo, e dos segmentos do turismo religioso e cultural. No estudo, se pretendeu demonstrar as implicações espaciais da atividade turística e a diversidade de expectativas de cada grupo de agentes promotores dos processos de turistificação de espaços relacionados à fé católica, enfatizando-se o Círio de Nazaré. Dentre as implicações espaciais observadas, destacam-se as intervenções permanentes realizadas no entorno da Basílica de Nazaré e as alterações temporárias, que se dão durante a realização da festividade, a exemplo da instalação de arquibancadas e da realização eventos paralelos, ambas visando à ampliação da sua atratividade turística.
\end{abstract}

Palavras-chave: Turismo; Círio de Nazaré; Espaço; Território; Turistificação; Turismo religioso e cultural.

ABSTRACT - This article approaches the Círio de Nazaré in Belém (Pará-PA, Brazil), one of the biggest cities in Amazon region, seeking its relationship with the tourism practices found in this events complex. The research occurred between 2012 and 2014 and it was complemented with official data in 2015. The methodology used was the literature review about the Círio de Nazare festivity, the geographic space and its appropriation for tourism, and religious and cultural tourism segments. This study was intended to demonstrate the spatial implications of tourist activity and expectations diversity of each group of promoter agents of space touristification space related to the catholic faith, emphasizing the Círio de Nazaré. Among the spatial implications observed, stands out the permanent interventions performed around the Basílica de Nazaré and the temporary changes that occur in the course of the festivity, like the installation of bleachers and the realization of parallel events, both with the intension of expanding the tourism attractiveness.

Key words: Tourism; Círio de Nazaré; Space; Territory; Touristification; Religious and cultural tourism.

\footnotetext{
"Formação: Graduação em Turismo (Bacharelado) pela Universidade Federal do Maranhão (UFMA), Especialização em Gestão Empreendedora pela Faculdade Ideal, Mestrado e Doutoranda em Geografia pela Universidade Federal do Pará (UFPA). Atividade profissional/acadêmica: Técnica de Planejamento e Gestão em Turismo na Secretaria de Estado de Turismo do Pará e bolsista pela Coordenação de Aperfeiçoamento de Pessoal de Nível Superior (Capes). Endereço Físico para correspondência: Rua Alacid Nunes, 100, Safira Park, Bloco L-401. Bairro: Tenoné. CEP: 66820-020 - Belém - Pará (PA) Brasil. E-mail: debserra1980@hotmail.com
} 


\section{INTRODUÇÃO}

Considerada uma das maiores manifestações católicas do mundo ${ }^{1}$, o Círio de Nazaré, em Belém do Pará (Brasil), é realizado há mais de duzentos anos (IPHAN, 2006) e ao longo desse período é possível observar transformações que lhe conferiram, além do caráter religioso, o cultural em sentido mais amplo, tornando-se, também, um dos maiores atrativos turísticos do Estado do Pará (PARÁ, 2011). Tais transformações foram realizadas por diversos agentes, que têm se apropriado de trechos do espaço, permanente ou temporariamente, tendo entre seus objetivos atrair um maior número de turistas, o que indica a ocorrência do processo de turistificação do espaço (FRATUCCI, 2008).

No presente artigo se visou abordar o Círio de Nazaré como um complexo de eventos que se tornou um expressivo atrativo turístico religioso e cultural na região amazônica, provocando implicações no espaço advindas do seu processo de turistificação, considerando as diversas expectativas de seus agentes promotores.

A pesquisa foi realizada entre os anos de 2012 e 2014, atualizando-a com dados oficiais de 2015. Os procedimentos metodológicos envolveram um levantamento bibliográfico acerca da festividade do Círio de Nazaré; do espaço como objeto de análise geográfica, para uma melhor compreensão do seu processo de turistificação; e dos segmentos do turismo religioso e cultural.

Assim, neste artigo se abordará inicialmente o Círio de Nazaré em Belém, a partir de sua origem, além de sua importância como atrativo turístico no Estado do Pará. Em seguida, tratar-se-á de considerações teóricas relativas ao espaço geográfico, ao turismo e aos processos de turistificação do espaço, relacionando tais considerações à festividade. Finalmente, serão abordados os segmentos do turismo religioso e cultural e suas implicações espaciais.

\footnotetext{
${ }^{1}$ REPRESENTAÇÃO DA UNESCO NO BRASIL. Disponível em: $<$ http://www.unesco.org/new/pt/brasilia/culture/world-heritage/intangible-cultural-heritage-listbrazil/cirio-de-nazare/\#c1415512 >. Acesso em: 15/11/2017.
} 


\section{O CÍRIO DE NAZARÉ EM BELÉM - PA}

De origem portuguesa, a devoção a Nossa Senhora de Nazaré disseminou-se pelas suas colônias, destacando-se, no Brasil, o Estado do Pará, no qual a santa é reverenciada em diversos municípios, tendo Belém, sua capital, como um dos um dos primeiros a cultuar e a realizar a festa em sua homenagem, o Círio de Nazaré, segundo o Instituto do Patrimônio Histórico e Artístico Nacional (IPHAN, 2006). Essa festividade se tornou uma das maiores manifestações católicas do mundo, conforme a Organização das Nações Unidas para a Educação, a Ciência e a Cultura, tendo sido inscrita na Lista representativa do Patrimônio Imaterial da Humanidade da referida entidade, em 2013 (UNESCO, 2013).

Quanto às estatísticas, estudos realizados em parceria entre a Companhia Paraense de Turismo - PARATUR, extinta em 2014, a Secretaria de Estado de Turismo - SETUR, e o Departamento Intersindical de Estatística e Estudos Socioeconômicos DIEESE (PARÁ 2010, 2011, 2012 e 2016), além dos trabalhos realizados por Pantoja (2006) e Costa et al. (s/d) informam que seriam mais de dois milhões de participantes na procissão principal. Pantoja (2006), porém, verifica que tais estimativas apresentam incoerências por serem calculadas por instituições que fazem parte da organização do evento e pela falta de regularidade na sua realização.

Conforme IPHAN (2006), desde sua origem, em 1793, o Círio de Nazaré em Belém se relaciona com aspectos religiosos, políticos e econômicos, considerando-se que apesar da devoção à santa ter se iniciado por volta do ano de 1700, a primeira procissão registrada ocorreu quase cem anos mais tarde, após autorização de Portugal. Ela foi convocada pelo governador Francisco Coutinho, que realizou durante a festa uma feira de produtos regionais, para a qual foram convidados os habitantes do interior da província, na busca da Igreja e do Estado pelo controle da devoção popular.

Essa relação com o poder público modificou-se com o advento da república, quando o Brasil se torna oficialmente um Estado laico (IPHAN, 2006). Entretanto, conforme Pantoja (2006), os governos estadual e municipal continuaram a se envolver nesse evento, sendo considerados pela Diretoria da Festa - grupo ligado à Igreja responsável pelos eventos mais associados aos aspectos sagrados dessa festividade como entidades realizadoras. Desse modo, o caráter religioso do Círio relaciona-se, em 
grande parte, à sua organização pela Diretoria da Festa. Porém, a Igreja busca exercer o controle também sobre as festas profanas. Ademais, ainda conforme Pantoja (2006), destaca-se o caráter popular dessa festividade, em que os fiéis nem sempre se subordinam ao poder da Igreja.

Observa-se, ainda, a dinamização econômica ocasionada pelo referido evento, tanto por ele atrair muitos visitantes, quanto pelo uso da "marca" Círio de Nazaré por empresas, buscando aumentar as vendas de seus produtos e serviços (PANTOJA, 2006).

Quanto à dimensão espacial do evento, o percurso das primeiras procissões ligava a ermida da santa, atual Basílica de Nazaré, ao palácio do governo, posteriormente, Museu Histórico do Estado do Pará, mas novas romarias foram criadas expandindo-se o território dessa festividade (IPHAN, 2006).

Registrado em 2004 pelo Instituto do Patrimônio Histórico e Artístico Nacional - IPHAN como Patrimônio Cultural de Natureza Imaterial, o Círio de Nazaré foi estudado pelo referido órgão que elaborou o Dossiê IPHAN I (2006), no qual são elencados os elementos da festividade considerados essenciais, seja por sua sacralização, simbolismo, antiguidade ou notável afluência popular. No Quadro 1, elaborado por Castro e Serra (2011, p. 4) com base nesse Dossiê, observam-se grande parte desses elementos, sendo que os que foram classificados como "demais elementos" podem tornar-se "essenciais" no decorrer dos anos.

\begin{tabular}{|l|l|}
\hline ELEMENTOS ESSENCIAIS & $\begin{array}{l}\text { Procissão Principal, Imagens (original e peregrina), Trasladação, } \\
\text { Berlinda, Corda, Recírio, Arraial, Almoço do Círio, Alegorias, } \\
\text { Brinquedos de Miriti. }\end{array}$ \\
\hline DEMAIS ELEMENTOS & $\begin{array}{l}\text { Missa do Mandato, Visitas da Santa aos Fiéis, Traslado para } \\
\text { Ananindeua e Marituba, Romaria Rodoviária, Romaria Fluvial, Moto } \\
\text { e a Ciclo Romaria, Descida e Subida da Imagem, Romarias da } \\
\text { Juventude e das Crianças, Procissão da Festa, Auto do Círio, Arrastão } \\
\text { do Boi Pavulagem, Festa da Chiquita. }\end{array}$ \\
\hline
\end{tabular}

QUADRO 1 - ELEMENTOS REPRESENTATIVOS DO CÍRIO DE NAZARÉ

FONTE: Castro e Serra (2011).

No referido estudo de Castro e Serra (2011), o qual teve por base IPHAN (2006), tais elementos são descritos em ordem cronológica. Eles afirmam que, iniciando a festividade nazarena, tem-se a Missa do Mandato, no mês de agosto, e em setembro são realizadas as visitas das imagens às casas dos fiéis. Prosseguem afirmando que no mês de outubro se concentra a maior parte das manifestações, em geral, com a presença da imagem peregrina, visto que a imagem original fica na Basílica de Nazaré. 
Ainda conforme os mencionados autores, a procissão principal é realizada no segundo domingo de outubro, mas ela é antecedida por diversos eventos ocorridos desde a sexta-feira, como o Traslado que ocorre desde 1992 levando a imagem da Basílica de Nazaré para o município de Ananindeua. Sua extensão até Marituba ocorreu em 2002 (IPHAN, 2006). Castro e Serra (2011) afirmam que, após percorrer alguns bairros, a romaria finaliza-se na Igreja Matriz de Ananindeua e que, na sexta, ocorre também o Auto do Círio, que é um cortejo cultural realizado por artistas locais retratando o sagrado e o profano, no bairro da Cidade Velha, seguindo da Praça do Carmo até a Praça D. Pedro II.

$\mathrm{Na}$ mesma fonte consta que a maior parte dos eventos ocorre no sábado, iniciando-se com a Romaria Rodoviária, que parte da Igreja Matriz de Ananindeua e leva a imagem até o distrito de Icoaraci, onde se realiza uma missa, dando início à Romaria Fluvial que leva a imagem de volta para a sede de Belém. Chegando na Escadinha do Porto, próximo à Estação das Docas, bairro da Campina, iniciam-se dois eventos concomitantes: o Arrastão do Círio, de caráter profano, e a Moto Romaria, com aspecto e motivação mais religiosos, ainda conforme a mesma fonte. $\mathrm{O}$ arrastão do Círio, cortejo que retrata a cultura popular regional, segue para a Praça do Carmo passando pelo Mercado do Ver-o-Peso, enquanto a Moto Romaria conduz a imagem até o Colégio Gentil Bittencourt, em Nazaré, de onde ela segue no fim da tarde para a Igreja da Sé, na Trasladação, a qual, após passar pela Praça da República, dá início à Festa da Chiquita, que é marcada principalmente pela presença de homossexuais e simpatizantes que se divertem ao som de músicas de vários estilos, sendo essa manifestação repudiada pela Diretoria da Festa e pelas autoridades da Igreja (CASTRO \& SERRA, 2011). No mesmo dia, de acordo com a mesma fonte, ocorre, na Basílica de Nazaré, a cerimônia da Descida da Imagem, em que a imagem original fica mais próxima dos fiéis.

Conforme Castro e Serra (2011), no domingo ocorre a principal procissão, chamada de Círio, levando a imagem da Sé, no bairro da Cidade Velha, à Basílica, em Nazaré, tendo como importantes elementos, assim como na Trasladação, a berlinda, a corda, as alegorias e os brinquedos de miriti. Estes são vendidos em diversos espaços da festividade, chamando atenção pelo seu colorido, sendo produzidos com o caule dessa palmeira, também conhecida como buriti, sobretudo no município de Abaetetuba, próximo a Belém (CASTRO; SERRA, 2011). Os referidos autores continuam 
afirmando que, ao seguirem para casa, os fiéis tradicionalmente se reúnem em família para o almoço do Círio, mas que, ao contrário da maioria das festas de santos, a procissão principal do Círio não finaliza a festividade, que se estende por quinze dias, nos quais são realizadas a Ciclo Romaria, as romarias das Crianças e da Juventude, a Subida da Imagem, e a Procissão da Festa. Quinze dias após a procissão principal, ocorre a última procissão, o Recírio, que conduz a imagem peregrina da Basílica de volta para o Colégio Gentil Bittencourt, onde ficará até o ano seguinte (CASTRO \& SERRA, 2011).

Ainda de acordo com Castro e Serra (2011), esta complexidade de eventos, pelo menos no que se refere aos aspectos sagrados, tornou necessária a formação de um grupo que se responsabilizasse pela sua organização, papel exercido pela Diretoria da Festa. A mesma fonte informa que, no fim da festividade, este grupo já inicia os preparativos para o ano seguinte e que os recursos para a realização do Círio são obtidos por meio de financiamentos dos governos estadual e municipal, além de patrocínios de empresas e doações dos fiéis.

A partir do processo de expansão do Círio de Nazaré em 1986, com a criação da Romaria Fluvial, amplia-se a apropriação temporária de trechos do espaço em diversos bairros de Belém, no distrito de Icoaraci e em parte dos municípios de Ananindeua e Marituba, com o objetivo de se realizar a extensa programação desse complexo de eventos, principalmente no segundo final de semana de outubro (IPHAN, 2006).

Tanto as ruas que compõem os trajetos das romarias e cortejos, como as que ficam próximas (paralelas e transversais) têm seu tráfego de veículos proibido, alterando-se o trânsito da cidade principalmente nos bairros centrais da Cidade Velha, Campina e Nazaré, nos quais se concentra a maior parte dos eventos. (IPHAN, 2006).

A dimensão espacial das manifestações que ocorrem no segundo final de semana de outubro, no qual se concentra a maior parte dos eventos, pode ser observada nos mapas das figuras 1 e 2 com os percursos das romarias, de aspectos sagrados, e dos cortejos, considerados profanos. 


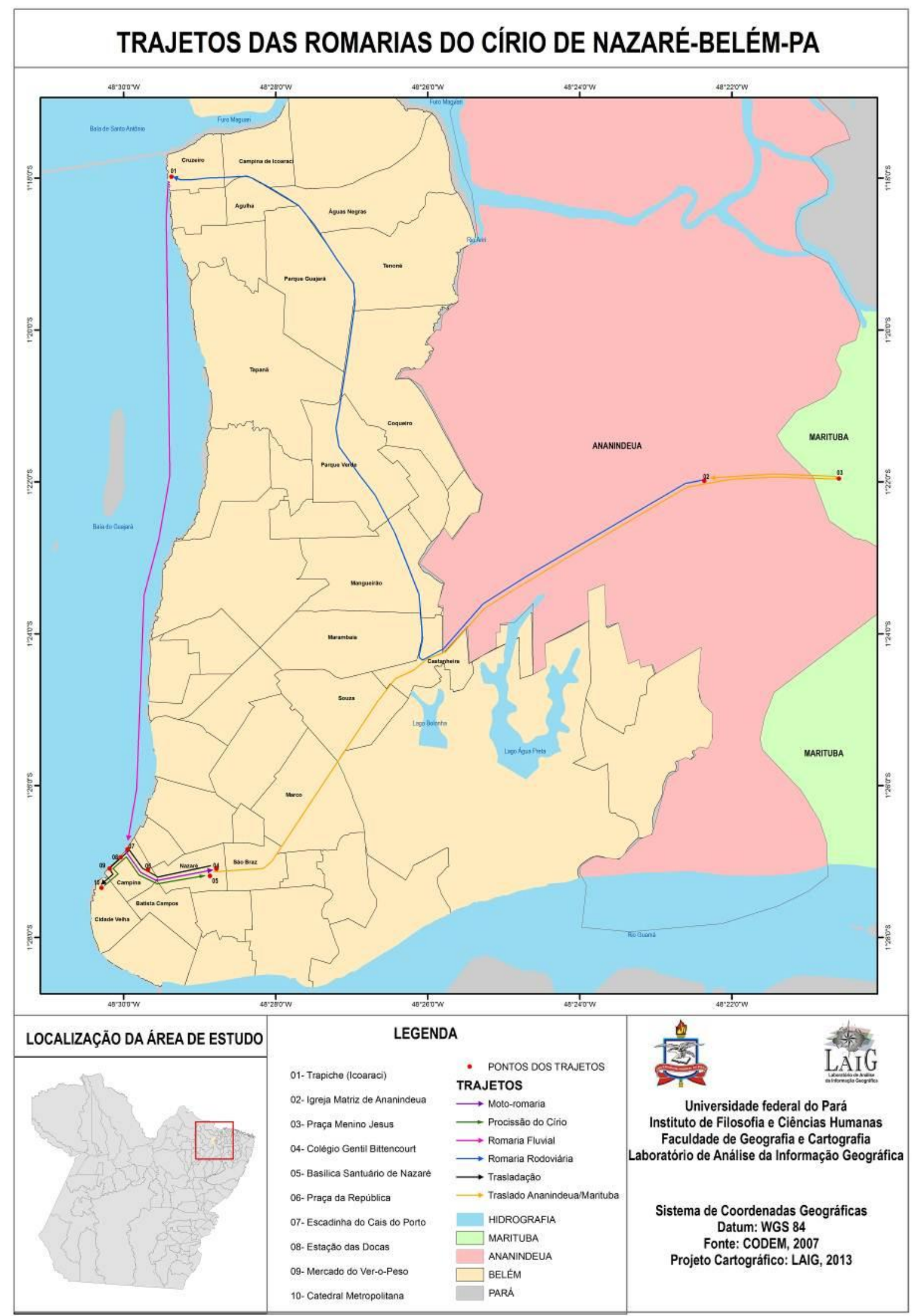

FIGURA 1 - TRAJETO DAS ROMARIAS DO CÍRIO DE NAZARÉ - BELÉM-PA FONTE: LAIG/UFPA - Organizado pela autora, 2013. 


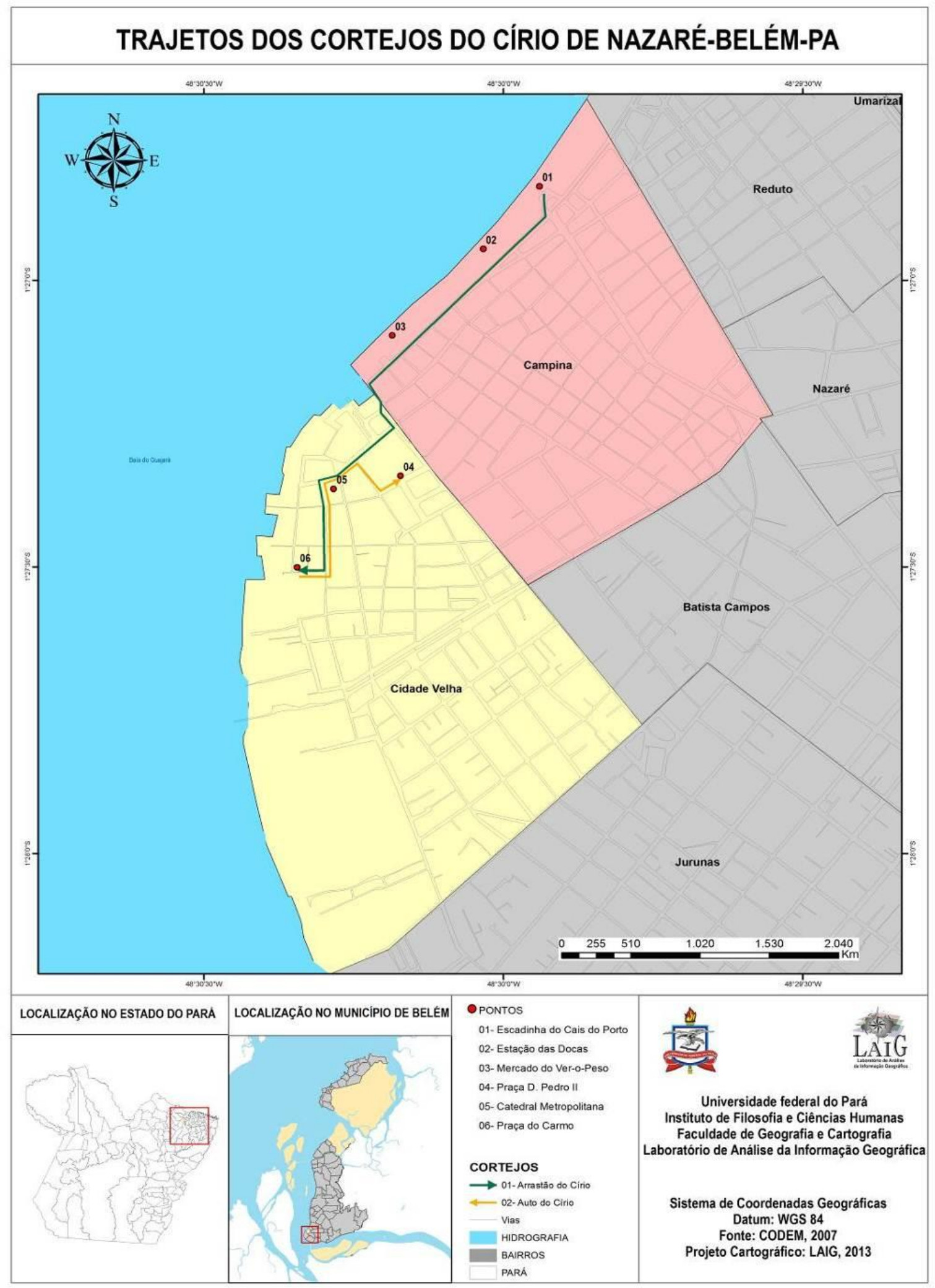

FIGURA 2 - TRAJETO DOS CORTEJOS DO CÍRIO DE NAZARÉ - BELÉM-PA FONTE: LAIG/UFPA - Organizado pela autora, 2013. 
Parte dos espaços apropriados pelos organizadores do Círio durante a sua realização são atrativos turísticos belenenses. No distrito de Icoaraci, destaca-se o Trapiche, onde se realiza a missa que inicia a Romaria Fluvial. É localizado na Orla, espaço estruturado com calçadão, bares, restaurantes e quiosques para a venda de artesanato, principalmente as cerâmicas marajoara e tapajônica.

Na sede do município de Belém, os eventos concentram-se em três bairros nos quais os espaços apropriados são considerados turísticos tanto pela sua relação com as festividades do Círio de Nazaré, como principalmente por sua importância na formação histórica e sócio-espacial da cidade. Assim, observam-se os percursos que envolvem a Basílica de Nazaré e o Colégio Gentil Bitencourt no bairro de Nazaré; as Praças do Carmo e D. Pedro II e a Igreja da Sé, na Cidade Velha, e, finalmente, a Praça da República e a Escadinha do Cais do Porto (onde se finaliza a Romaria Fluvial), localizadas no bairro da Campina. Ainda no referido bairro destaca-se o Complexo do Ver-o-Peso e a Estação das Docas como parte do trajeto de algumas romarias e cortejos.

Quanto à atividade turística, o número de visitantes no período do Círio dinamiza diversos setores da economia paraense, gerando-se emprego e renda. Conforme o Quadro 2, estudos da PARATUR e do DIEESE indicam que o número de turistas que visitam Belém durante o Círio aumenta a cada ano.

\begin{tabular}{|l|c|c|}
\hline ANO & NÚMERO DE TURISTAS & GASTO PRESUMIDO \\
\hline 2010 & Cerca de 69 mil & U\$ 25 milhões \\
\hline 2012 & Cerca de 76 mil & U\$ 28 milhões \\
\hline 2015 & Cerca de 83 mil & U\$ 31 milhões \\
\hline
\end{tabular}

Observando que no período de realização do Círio ocorre um significativo aumento no fluxo de visitantes, que diversas manifestações da cultura paraense se evidenciam e que os agentes do Estado, da Igreja e do mercado turístico alteram e se apropriam de trechos do espaço urbano de Belém, utilizando elementos culturais da festa com objetivos diversos, julgou-se ser necessário abordar a seguir algumas considerações teóricas referentes ao espaço e sua relação com a atividade turística. 


\section{O ESPAÇO E SUA TURISTIFICAÇÃO: REFLEXÕES SOBRE O CÍRIO DE NAZARÉ}

As concepções de espaço geográfico são diversas e sua importância como conceito-chave para a geografia alterou-se de acordo com as correntes de pensamento, o que foi tratado por Corrêa (2008). Ele observa que as correntes da geografia humanística e crítica, que surgiram na década de 1970, se assemelham entre si no rompimento com o positivismo, embora a primeira faça uso da fenomenologia e do existencialismo, enquanto a segunda se baseie no materialismo histórico dialético, o que torna bastante evidente as diferenças de concepções de espaço para cada uma delas.

Para Mello (1990), a experiência vivida é a ferramenta de trabalho para os geógrafos humanistas, que em suas análises, buscaram definir o significado de espaço, mas também o de lugar. Nessa perspectiva, espaço seria "qualquer porção da superfície terrestre, é amplo, desconhecido, temido ou rejeitado" (MELLO, 1990, p. 102). E continua, dando ao lugar a característica de ser "recortado afetivamente, emerge da experiência e é um mundo ordenado e com significado" (MELLO, 1990, p. 102).

$\mathrm{Na}$ geografia crítica podem-se destacar, de acordo com Corrêa (2008), as contribuições de Henri Lefébvre ${ }^{2}$ e de Milton Santos ${ }^{3}$. Em relação à concepção de Lefebvre, Corrêa (2008, p. 25) observa que "o espaço é o lócus da reprodução das relações sociais de produção", enquanto para Milton Santos, também inspirado em parte em obras de Lefébvre, há a busca a superação da dicotomia entre sociedade e espaço a partir do seu conceito de formação sócio-espacial ou apenas espacial.

A contribuição de Milton Santos para a compreensão do espaço está contida em diversas obras. Para ele "o espaço é formado por um conjunto indissociável, solidário e também contraditório, de sistemas de objetos e sistemas de ações, não considerados isoladamente, mas como o quadro único no qual a história se dá (SANTOS, M., 2006, p. 39)". Assim, objetos e ações não podem ser concebidos isoladamente, a não ser para se facilitar uma análise abstrata, mas com a convicção de que um interfere no outro, afinal,

\footnotetext{
${ }^{2}$ LEFÉBVRE, H. Espacio y Política. Barcelona: Ediciones Peninsula, 1976.

${ }^{3}$ SANTOS, M. Society and Space: social formation as Theory and Méthod. Antípode, Wocester, n.1, v. 9, p. 3-13, 1977.
} 
os objetos são criados a partir das ações e estas são originadas pelas necessidades humanas. O autor destaca, ainda, a intencionalidade que há entre a ação e o objeto.

$\mathrm{Na}$ mudança na postura do pensamento geográfico, o espaço passou a ser discutido no processo de renovação dessa ciência e se tornou um ponto de partida para estudos mais voltados à criticidade, nos quais a sociedade é protagonista do processo de produção do espaço. E, nesse sentido, encontram-se discussões envolvendo os mais diversos temas, dos quais se destacam nesse trabalho o turismo e a religião.

No que se refere à relação turismo-espaço, Ivars (2003) afirma que a atividade turística é um fato social e econômico manifestado claramente no espaço e que seu caráter espacial é determinado pelo deslocamento de pessoas de seu lugar de origem até o destino e que provocam diversos efeitos sobre os territórios.

Tratando-se de um fenômeno complexo, não se pode eleger uma única definição para o termo turismo. Porém as definições em geral apontam para necessidade do deslocamento, o tempo de duração da viagem e as motivações. A espacialidade da atividade turística perpassa pela necessidade de deslocamento dos turistas para os destinos; pela criação de novos objetos geográficos ou pela refuncionalização dos préexistentes e possíveis alterações em sua distribuição espacial; e pela necessidade da diferenciação do espaço turístico como fator de competitividade (SILVA; FONSECA, 2010).

Os fenômenos espaciais são geograficamente estudados a partir de categorias dentre as quais, destaca-se nas análises geográficas sobre os processos de turistificação de espaços, a de território, considerando-se a atuação dos agentes e suas estratégias de apropriação de porções espaciais.

Com base em Haesbaert (2004), verifica-se a existência de diversas concepções sobre a categoria território. Elas são trazidas pelo referido autor em sua discussão sobre a multiterritorialidade. Para ele, esta categoria contém relações de dominação e/ou de apropriação e "desdobra-se ao longo de um continuum que vai da dominação políticoeconômica mais 'concreta' e 'funcional' à apropriação mais subjetiva e/ou 'culturalsimbólica"'(HAESBAERT, 2004, p. 95-96). Por integrar as perspectivas materialistas e idealistas, dando importância tanto ao poder político-econômico, quanto ao simbólico, essa concepção será utilizada por Fratucci (2008), em sua análise sobre a turistificação do espaço, a qual será fundamental para o presente estudo, assim como estudos 
geográficos relacionando turismo e território, dos quais foram destacados Knafou (1996) e Cruz (2001 e 2007).

Buscando abordar cientificamente a atividade turística, Knafou (1996) tratou das relações entre turismo e território apontando três possibilidades: os territórios sem turismo, o turismo sem território e os territórios turísticos. Os territórios sem turismo eram comuns até o que o autor coloca como "invenção" do turismo no século XVIII na Europa, mas com as facilidades de acesso pelo desenvolvimento dos transportes, eles se tornaram cada vez mais raros. O turismo sem território se refere àquele que não resulta da iniciativa dos turistas, mas sim de operadores turísticos, onde os turistas não se apropriam do espaço, construídos geralmente em lugares de passagem [tal] tais como os "Center Parcs" criados no noroeste da Europa. Já os territórios turísticos seriam aqueles criados pelos turistas e de certa forma retomados pelos operadores e planejadores da atividade.

Em relação aos territórios sem turismo, $\operatorname{Cruz~(2001,~p.~18)~afirma~que:~}$

Apesar da expansão territorial da atividade turística e da mobilidade espacial de turistas [...], há inúmeros lugares no mundo que não foram apropriados pelo turismo. Certa seletividade espacial orienta a eleição, pelo turismo, de determinados pontos do território em cada momento histórico.

Complementando essa abordagem, ressalta-se que para Cruz (2007), a expressão "território turístico" não existe teoricamente, mas sim os "usos turísticos do território" uma vez que a apropriação de porções dos espaços ocorre por diversas atividades ao mesmo tempo, incluindo-se e destacando-se em alguns casos o turismo. Nesse sentido, em relação ao Círio de Nazaré em Belém, apesar de sua importância como atrativo turístico, os espaços utilizados para a sua realização são apropriados por agentes de diversas atividades, desde religiosas a comerciais, não necessariamente vinculadas à atividade turística. Todavia o uso turístico do território se destaca na Romaria Fluvial, a qual, conforme IPHAN (2006), foi criada pela PARATUR e nela o espaço fluvial é apropriado por diversos agentes do mercado turístico.

Ao tratar do Círio em uma abordagem territorial, dada a sua complexidade e o caráter temporário da apropriação de diversos espaços para a sua realização, reporta-se à expressão "território móvel", que parte das observações de Souza (2003) de que os territórios podem ou não ter um caráter permanente. Para ele os territórios são "antes 
relações sociais projetadas no espaço que espaços concretos [...]" podendo "formar-se e dissolver-se, constituir-se e dissipar-se de modo relativamente rápido [...] e isto apesar de que o substrato espacial permanece ou pode permanecer o mesmo" (SOUZA, 2003, p. 87).

A abordagem territorial da atividade turística está relacionada com os processos de turistificação do espaço uma vez que ela é consumidora de porções do espaço consideradas privilegiadas que são apropriados pelos seus agentes sociais. Nesse sentido, relacionando-se com a definição de território proposta por Haesbaert (2004) apresentada anteriormente, Fratucci (2008, p. 53) afirma que:

\footnotetext{
O processo de turistificação dos espaços [...] compreende tanto o processo de apropriação simbólica de trechos do espaço pelo turista (a partir de "olhares" diferenciados social, política e culturalmente), como o processo de dominação pelos agentes econômicos e pelos agentes de governo.
}

Knafou (1996) contribui para os estudos sobre a turistificação dos espaços ao apontar as três fontes maiores desse processo, que seriam os turistas, o mercado e os planejadores e promotores “territoriais". Fratucci (2008), porém, amplia a concepção de agentes de turistificação, pois além dos turistas, agentes do mercado e Estado, ele inclui as comunidades receptoras, visto que, de acordo com suas características, necessidades e expectativas, e agindo e interagindo sincronicamente, todos eles podem interferir no curso da atividade turística.

De modo análogo ao que foi colocado por Knafou (1996), Fratucci (2008) afirma que o turista é o agente social gerador do fenômeno turístico. Todavia, este autor aprofunda a análise explicando que o turista se desterritorializa temporariamente a partir do seu deslocamento para outros pontos do espaço por motivações diversas, produzindo, dessa forma, territórios mais fluidos e sazonais, além de movimentar a cadeia econômica ligada à satisfação de suas necessidades.

Ao tratar dos agentes do mercado ou do trade turístico, o autor afirma que com as necessidades dos turistas e por meio dos empresários o capital mercantilizou o fenômeno turístico transformando-o em mais uma atividade econômica. Tais necessidades permitem a divisão desses agentes entre os que se relacionam diretamente com os turistas (proprietários de meios de hospedagem, restaurantes etc.) e os indiretamente relacionados (empresários do ramo de comunicação, segurança etc.). 
Ao Estado, em seus diferentes níveis de governo, cabe a normatização e regulação da atividade de modo a atender os interesses da população local atentando ao mesmo tempo para a lógica do capital.

A comunidade receptora, geralmente ignorada pelos estudiosos como um agente de turistificação, foi agrupada por Fratucci (2008) entre os que trabalham diretamente na atividade turística, os trabalhadores indiretos e a população residente não envolvida com o turismo.

É necessário observar que tais agentes atuam em maior ou menor grau nos processos de turistificação. Cruz (2007) afirma que os agentes hegemônicos seriam o Estado e o mercado, tendo muitas vezes o primeiro uma postura de subserviência em relação ao segundo. Ela acrescenta, porém, que "a hegemonia de um ou de outro não anula as possibilidades de contramovimentos" (CRUZ, 2007, p. 11) referindo-se às reações da sociedade civil organizada. E reconhece o papel dos turistas tanto por serem a razão da atuação do Estado e do mercado, como por serem responsáveis pela invenção de muitos destinos turísticos.

Em relação ao Círio de Nazaré em Belém, Frugoli e Bueno (2014, p. 151) observam que:

\footnotetext{
Desde a sua origem, a festa do Círio de Nazaré foi passando por grandes transformações, mas não perdeu o seu caráter confraternizador e ainda congrega a população de maneira abrangente, sendo um acontecimento que envolve direta ou indiretamente a população além dos limites do Estado do Pará.
}

Assim, o processo de turistificação do espaço no que se refere ao Círio de Nazaré envolve os agentes identificado por Fratucci (2008) e verifica-se que tanto o poder público, representado pelos órgãos de cultura e turismo municipais e estaduais, como a Igreja Católica e os agentes do mercado direta ou indiretamente relacionados ao turismo, agem em parceria para tornar essa festividade mais atrativa não apenas turisticamente.

Tal parceria foi observada por Pantoja (2006) ao tratar das dimensões e dos agentes promotores da festividade, em relação à programação oficializada pela Diretoria da Festa. Nesse sentido, além da contribuição da prefeitura e do governo do Estado, os empresários podem obter cotas como patrocinadores ou apoiadores oficiais do Círio. 
Para a autora, os possíveis interesses dos agentes são de ordem religiosa, política e/ou econômica, sendo que tais interesses não são excludentes um em relação ao outro.

Quanto aos turistas no período do Círio, observa-se a carência de dados quantitativos, considerando-se que de acordo com Costa et al. (s./d.) as pesquisas não contemplam satisfatoriamente os turistas que chegam pela via fluvial. A necessidade de dados qualitativos se refere, por exemplo, às suas motivações, aos espaços e eventos frequentados por eles, considerando-se tanto o caráter sagrado quanto profano da festa. No último estudo divulgado, referente ao Círio 2015 (PARÁ, 2016), o perfil da maioria dos turistas era nacional, do sexo feminino (com diferença de apenas 2 por cento para os de sexo masculino) e com renda mensal entre cinco a oito salários mínimos. Aproximadamente metade dos entrevistados hospedou-se em hotéis e quarenta por cento dos demais em casas de parentes e amigos.

Entre os agentes do mercado diretamente relacionados à atividade turística (o chamado trade turístico), destacam-se os das agências de viagens, principalmente no que se refere à venda dos chamados pacotes para a Romaria Fluvial, e os hoteleiros, especialmente os responsáveis pelos estabelecimentos situados no percurso das romarias, os quais preparam arquibancadas e refeições, com elementos da gastronomia paraense, que são comercializados entre turistas e população local. (CASTRO; SERRA, 2011).

Todavia, deve-se observar a atuação indireta de empresários não pertencentes ao trade turístico na indução de fluxos de turistas para Belém no Círio. Suas ações contribuem para a espetacularização e amplitude da festividade, onde se destacam aqueles ligados às mídias e aos patrocinadores e a apoiadores oficiais, nos quais se incluem instituições como bancos, redes de supermercado, shoppings, entre outros. Para Moraes e Gândara (2016), o trabalho dos agentes midiáticos na atividade turística busca atrair o visitante por meio de vivências extraordinárias, o que se relaciona ao chamado turismo de experiência, desenvolvido por profissionais de marketing.

Os agentes do poder público devem ser considerados de acordo com as esferas municipal, estadual e federal de governo. Entende-se que além da Prefeitura Municipal de Belém e do Governo do Estado do Pará, por meio de seus órgãos de cultura e turismo, considerados pela Diretoria da Festa como entidades realizadoras do Círio, o 
IPHAN, órgão federal, contribui para o processo de turistificação devido, principalmente ao seu registro como patrimônio cultural.

Nesse sentido, considerando-se que para Cruz (2007) a atuação do Estado para favorecer o turismo vai além da criação de novos objetos e da adequação dos preexistentes, verifica-se que no Círio os referidos agentes do poder público das esferas estadual e municipal também atuam no sistema de ações com a qualificação profissional e a divulgação da festividade nacional e internacionalmente.

Tal como apontado por Fratucci (2008), as comunidades das áreas receptoras seria formada pelos trabalhadores diretos e indiretos do turismo e a população residente não envolvida com essa atividade, da qual se destaca aquela mais diretamente impactada: os moradores dos bairros onde se concentra a maior parte das manifestações.

Dada a complexidade do Círio de Nazaré, podem ser incluídos outros agentes, que são parte das chamadas comunidades das áreas receptoras, mas que têm atuação diferente da maioria, tais como os agentes culturais e as entidades envolvidas na organização dos eventos religiosos.

Os agentes culturais, mais ligados aos eventos profanos, são diversos. Dessa forma, considerando-se os elementos representativos da festividade, podem-se considerar os responsáveis pelo Auto do Círio, Arrastão do Círio e Festa da Chiquita, além de fabricantes e vendedores de brinquedos de miriti.

No que se refere ao caráter sagrado do Círio, a organização dos eventos é realizada, desde 1910, pela Diretoria da Festa, a qual, conforme IPHAN (2006) é formada por representantes da Igreja e de vários segmentos da sociedade belenense, todos do sexo masculino, embora as esposas dos diretores realizem diversas atividades relacionadas à festividade.

Tratando-se da hegemonia de alguns agentes, que conforme Cruz (2007) seriam o Estado e os agentes de mercado, a Diretoria da Festa pode ser incluída ao se tratar do processo de turistificação do espaço no Círio de Nazaré.

Assim, o referido processo contempla diversos agentes, que em dados momentos apresentam-se em conflito, por exemplo, entre religiosos e organizadores de eventos profanos. Contudo, verifica-se também a parceria entre o poder público, a Igreja Católica e os agentes de mercado, principalmente no que se refere ao financiamento para a realização da festividade, visando torná-la mais atrativa inclusive turisticamente. 
Voltando aos estudos de Fratucci (2008), o autor observa que a atividade turística provoca transformações no ordenamento dos espaços apropriados por ela, a exemplo da substituição das atividades primárias pelas de prestação de serviços e construção de empreendimentos de lazer, que podem gerar efeitos negativos para a cultura e para o meio ambiente natural, entre outros, além de conflitos entre grupos sociais locais, turistas e agentes do mercado turístico. E tais efeitos tendem a inviabilizar a permanência dessa atividade.

Ele acrescenta ainda que, devido aos efeitos positivos na economia de diversos países, principalmente dos chamados de emergentes, o poder público (aqui entendido como agentes das esferas estaduais e municipais de alguns Estados brasileiros) tem colocado tal atividade como uma das prioridades em seus planos de governo, o que para o referido autor é uma incoerência.

Considerando-se os efeitos positivos e negativos da atividade turística, muitos deles advindos da supervalorização de sua importância econômica, enfoca-se, a seguir, as implicações espaciais do turismo voltando-se para os segmentos cultural e religioso.

\section{O TURISMO RELIGIOSO E CULTURAL E SUAS IMPLICAÇÕES ESPACIAIS}

Conforme explicitado anteriormente, o Círio de Nazaré em Belém atrai milhares de turistas no período de sua realização e, considerando que eles visitam diversos pontos turísticos da cidade, conforme Pará (2012, 2016), infere-se que suas motivações não são apenas religiosas.

Devido à intensa proximidade entre os segmentos do turismo religioso e do cultural, o Ministério do Turismo considera que o religioso se trata de um dos tipos de turismo cultural, mas que decorre "da busca espiritual e da prática religiosa em espaços e eventos relacionados às religiões institucionalizadas [...]" (BRASIL, 2010, p. 19). O referido Ministério considera apenas como turismo cultural a experiência realizada por turistas que viajam para eventos ou espaços religiosos tendo como motivação o interesse cultural ou a apreciação estética, ou seja, sem a busca pela prática religiosa. 
Santos, Maria (2006) aponta para a escassez de estudos geográficos acerca do turismo religioso e de sua dimensão espacial, afirmando que, em sua maioria, as investigações realizadas estão ligadas à geografia da religião, mais voltadas às peregrinações, sendo raras as pesquisas no âmbito da geografia do turismo.

A referida autora problematiza a questão do turismo religioso ao compará-lo com o antigo fenômeno das peregrinações. Observando a aproximação entre eles no sentido de que ambos ocorrem por motivações religiosas, dividem espaços tidos como sagrados e utilizam geralmente da mesma infraestrutura e dos serviços nos destinos, a distinção entre eles, ainda conforme ela, se daria pela intensidade da motivação religiosa. No caso da peregrinação, o próprio deslocamento já é uma prática religiosa, enquanto para o turista religioso ela seria um meio para se chegar aos lugares marcados pela espiritualidade (SANTOS, Maria, 2006).

Rosendahl (2002) trata das peregrinações católicas e traz exemplos de alguns centros onde o aspecto turístico pode ser associado ao religioso. Para ela, contudo, as peregrinações no Brasil guardam, "na quase unanimidade dos casos, uma característica evidentemente religiosa, assumindo o sentido de sacrifício" (ROSENDHAL, 2002, p. $4)$.

Buscando incluir os principais traços característicos do que se pode considerar como turismo religioso, Santos, Maria (2006, p. 293) o define como:

[...] toda e qualquer deslocação (voluntária, temporária e não remunerada) religiosamente motivada, combinada com motivações de outro tipo, que tem por destino um lugar religioso (de âmbito local, regional, nacional e internacional), mas que não é em si uma prática religiosa.

Retomando a discussão sobre a proximidade entre o turismo religioso e o cultural, a referida autora explica ainda que, como as religiões geralmente são responsáveis por grande parte da herança arquitetônica e artística criada pela humanidade, é comum a prática do turismo cultural em espaços religiosos, motivado pela intenção intelectual ou ainda pela busca pelo prazer estético.

A dificuldade para se distinguir as motivações dos visitantes, que podem ir além das religiosas e culturais, torna-se maior, segundo a autora, quando se trata da realização das tradicionais festas religiosas que, em geral, incluem programações profanas. Nesse sentido, se pode exemplificar com o presente objeto de estudo, o Círio de Nazaré, 
considerando-se a importância de se fazerem pesquisas que demonstrem em que medida o interesse principal dos visitantes tem um caráter mais voltado à espiritualidade.

Observa-se, contudo, que no Círio de Nazaré, embora haja a necessidade de dados estatísticos, é comum a presença de peregrinos (especialmente na procissão principal), turistas religiosos e turistas culturais.

Em relação à definição para o segmento do turismo cultural, considerando também a motivação principal para o deslocamento como critério na tentativa de segmentar a atividade turística, Barretto (2000, p. 29) utiliza o termo "turismo com base no legado cultural" para identificá-lo como "aquele que tem como principal atrativo o patrimônio cultural", entendido aqui tanto em relação aos seus aspectos materiais, como imateriais. Portanto, considera-se que o praticante deste segmento pode também ser atraído ao destino em menor medida por outras razões.

Em relação às alterações espaciais nos lugares turísticos, ocasionadas pelos diversos segmentos dessa atividade (dentre eles o religioso e o cultural), algumas delas são questionáveis devido principalmente às suas interferências junto à população local. Tem se como exemplo comum as transformações realizadas em centros históricos em atendimento às necessidades mercadológicas, buscando-se sua valorização estética e desconsiderando-se suas funções originais e a sua identificação com a parcela da população que o vivencia, conforme aponta Paes-Luchiari (2005).

Todavia, apesar dos possíveis efeitos negativos da atividade turística, Barretto (2000, p. 32) indaga se existe:

[...] alguma manifestação humana atualmente que não se transforme, de alguma maneira, num bem de consumo e sua transformação num bem de consumo não é preferível ao lento, mas inexorável, processo de destruição dos bens, ora diante da especulação imobiliária, ora em virtude da 'modernização' imposta pela indústria cultural e pela globalização da economia.

Entre as alterações espaciais provocadas pela atividade turística, apontam-se neste estudo as observadas em centros de peregrinações e realizações de festas religiosas católicas.

Santos, Maria (2006, p. 407) considera que a cidade de Fátima, em Portugal, por ser uma cidade-santuário e uma cidade de peregrinação, é também um centro de acolhimento de turistas, o que a caracteriza como um "espaço turístico". Nessa 
condição, a atividade turística se destaca das demais nos processos de ordenamento territorial. A referida autora faz um levantamento dos instrumentos de planejamento urbanístico da cidade bem como da evolução do aglomerado urbano da Cova da Iria, em função das necessidades que surgiram devido ao aumento do número de visitantes, bem como do crescimento da população residente. Tais alterações objetivaram, entre outros, facilitar o acesso aos lugares sagrados, ordenar os espaços de comercialização de produtos religiosos e souvenirs, além de ampliaram a oferta hoteleira.

Quanto aos santuários brasileiros, destaca-se o estudo de Oliveira (2004) sobre a cidade paulistana de Aparecida e a sua Basílica Nacional. O autor exemplifica algumas intervenções urbanas na cidade, principalmente na grande oferta hoteleira, e no santuário, que para receber milhões de visitantes anualmente possui museu, mirante, um imenso salão de ex-votos, lojas, livrarias, confessionários, ampla área de passeio e estacionamento, e um shopping com praça de alimentação. $\mathrm{O}$ autor deixa claro que a falta de participação de profissionais não religiosos no planejamento turístico da cidade a tornou "um atrativo tão caótico quanto qualquer grande cidade brasileira" (OLIVEIRA, 2004, p. 47).

Em relação ao culto a Nossa Senhora de Nazaré em Belém, conforme Figueiredo (2005), sua atratividade turística perpassa tanto pela sua importância religiosa, quanto pelo seu caráter profano, dado que esse complexo de eventos é considerado como parte da identidade cultural não apenas dos belenenses, como dos paraenses.

Em relação às alterações espaciais, observa-se que elas atendem a interesses de agentes como a Igreja, o Estado, e empresários, especialmente os patrocinadores e apoiadores, visando a uma maior atratividade turística a partir de apropriações com características permanentes ou temporárias. As alterações permanentes têm entre seus objetivos atrair visitantes para além do período da festividade e ocorreram no entorno do santuário, a partir da década de 1980, quando, de acordo com Matos (2010), cidades como Aparecida em São Paulo, entre outras, também se estruturaram para fortalecer o turismo religioso. A autora afirma que em 1982 houve a transferência do arraial, realizado desde o primeiro Círio na área em frente à atual Basílica Santuário, para uma área lateral, pertencente à Igreja e, em seu lugar, foi construído o Centro Arquitetônico de Nazaré - CAN com recursos da União. Ainda conforme a autora, a praça pública, onde ocorria o arraial, tornou-se um prolongamento da basílica e é controlada pela 
Diretoria da Festa, passando a se chamar Praça Santuário. Nessa intervenção destruíram-se equipamentos urbanísticos que estavam relacionados às práticas profanas, em um processo de "higienização", ficando aquele espaço destinado a shows musicais (predominantemente católicos) e à exposição da imagem peregrina durante a festividade. A mesma fonte se refere também à demolição dos bares do arraial em 2010, à inauguração de uma loja de souvenirs religiosos em área anexa à Basílica (onde anteriormente funcionava um restaurante) e à transformação dos arcos temporários na Avenida Nazaré em estruturas fixas, demarcando o território do santuário.

Pode-se apontar, ainda, a criação do Museu do Círio, em 1986, pelo governo do Estado (IPHAN, 2006). Em 2002, ele é transferido do subsolo da Basílica de Nazaré para o bairro da Cidade Velha, sendo instalado no complexo Feliz Lusitânia, o qual conforme Castro (2012, p.12) se tratou de uma das ações do referido governo que visava, além da preservação do patrimônio, “a dinamização de novas atividades econômicas e de lazer, que contribuem para o desenvolvimento de atividades turísticas no bairro". O atual acervo do museu inclui elementos sagrados e profanos relacionados ao Círio ${ }^{4}$.

Em 2012, a Diretoria da Festa criou no entorno da Basílica Santuário o memorial denominado Memória de Nazaré que, diferenciando-se do Museu do Círio, esse empreendimento retrata apenas os aspectos sagrados da festividade com a exposição de mantos, cordas, ex-votos, cartazes etc. ${ }^{5}$. Acredita-se que para o objetivo de se atrair turistas religiosos para além do período do Círio, essa ação foi considerada necessária por permitir que se tenham próximos objetos inter-relacionados: a basílica, o memorial, a loja de souvenirs e a Praça Santuário. Como continuidade de tais ações, em 2015, a prefeitura municipal atendeu ao pedido da Diretoria da Festa para que a rua localizada em frente à basílica fosse transformada em calçada, num prolongamento da Praça Santuário ${ }^{6}$.

\footnotetext{
${ }^{4}$ MUSEU DO CÍRIO. Disponível em: <http://www.secult.pa.gov.br/content/museu-do-c\%C3\%ADrio/>. Acesso em: 15/11/2017.

5 MEMÓRIA DE NAZARÉ. Disponível em: <http://ciriodenazare.com.br/site/turismo/memoria-denazare/>. Acesso em: 15/11/2017.

6 BASÍLICA SANTUÁRIO TERÁ CALÇAMENTO NOVO E ESTENDIDO. Disponível em: $<$ http://www.ormnews.com.br/noticia/basilica-santuario-tera-calcamento-novo-e-estendido>. Acesso em: 15/11/ 2017.
} 
Dentre as alterações espaciais temporárias destaca-se a instalação de arquibancadas pela Paratur em 1977, na Avenida Presidente Vargas, para que turistas e fiéis possam assistir a passagem da imagem (IPHAN, 2006), o que a aproxima de um espetáculo. A partir de notícias veiculadas pela internet, ${ }^{7}$ observa-se que a responsabilidade pela venda de ingressos para tais arquibancadas já foi da Coordenadoria Municipal de Turismo - BELEMTUR, e que posteriormente passou para a Diretoria da Festa.

A realização de feiras para a venda de brinquedos de miriti durante o Círio também se inclui entre as alterações (e apropriações espaciais) temporárias. Conforme Matos (2010), no início elas eram realizadas improvisadamente em espaços diversos, passando a receber o apoio da prefeitura de Belém a partir de 1997 e do Serviço Brasileiro de Apoio às Micro e Pequenas Empresas - SEBRAE a partir de 2006. Nesse momento os produtos passaram a ter maior visibilidade, ocupando-se espaços como a Praça Waldemar Henrique e a Estação das Docas, que podem ser considerados como parte dos percursos das principais romarias e cortejos (MATOS, 2010).

Assim, dado o caráter cultural das festividades religiosas, ressalta-se que a atratividade exercida pelo Círio o diferencia do segmento turístico tradicionalmente mais desenvolvido na Amazônia, o ecoturismo, que de acordo com Coelho (1998) tem seu discurso vinculado à visão da natureza dessa região como exótica e selvagem, desconsiderando-se a presença das sociedades que nela habitam.

Finalmente, considerou-se necessário esclarecer que as transformações advindas da atividade turística em espaços religiosos são geralmente realizadas ou apoiadas pela própria Igreja, que busca, entre outros, ampliar o número de fiéis a partir de tais ações. (MATOS, 2010). Todavia deve-se considerar também a atuação de agentes como o Estado, o trade turístico, a comunidade receptora e os próprios turistas, os quais, conforme seus interesses, podem ou não concordar com as referidas transformações.

\footnotetext{
7 ARQUIBANCADAS MAIS CARAS NO CÍRIO 2005. Disponível em: <http://ormtv.com.br/noticia.asp?noticia_id=101158>. Acesso em: 15/11/2017; INGRESSOS PARA ARQUIBANCADAS DO CÍRIO 2012 JÁ ESTÃO ESGOTADOS. Disponível em: <http://g1.globo.com/pa/para/cirio-de-nazare/2012/noticia/2012/10/ingressos-para-arquibancadas-docirio-2012-ja-estao-esgotados.html>. Acesso em: 15/11/2017.
} 


\section{CONSIDERAÇÕES FINAIS}

Os círios, termo comum na região amazônica para referir-se tanto a procissões como mais amplamente às festividades de santos, são realizados em diversos municípios, destacando-se o Estado do Pará, onde em sua capital, Belém, se reverencia a Nossa Senhora de Nazaré desde o início do século XVIII (IPHAN, 2006).

Com o objetivo de apresentar a complexidade desse evento, seus agentes e suas características que o inserem no processo de turistificação do espaço, observou-se que ele se tornou um dos principais atrativos turísticos no segmento cultural e, de modo mais específico, religioso, na região amazônica, sofrendo nítidas transformações advindas do referido processo.

Nesse sentido, compreendeu-se a festividade do Círio de Nazaré como um complexo de eventos de caráter sagrado e profano, os quais se concentram principalmente no segundo final de semana e outubro.

$\mathrm{Na}$ busca por uma abordagem sobre o Círio de Nazaré pautada principalmente na geografia do turismo, é possível utilizar-se como base os estudos de Fratucci (2008) sobre o processo de turistificação do espaço, que é realizado por diversos agentes: turistas, poder público, trade turístico e comunidade receptora.

Nesse estudo, verificou-se também a aproximação dos segmentos do turismo religioso e do cultural, sendo um considerado como subtipo do outro, havendo ainda a peregrinação, com características relacionadas mais estritamente à busca pelo sagrado. Apesar da falta de dados estatísticos nesse sentido, acredita-se que participem do Círio de Belém peregrinos e turistas.

Quanto às implicações espaciais ocasionadas pela turistificação, foram observadas transformações permanentes, especialmente as realizadas no entorno da Basílica de Nazaré, e temporárias, representadas pela instalação de arquibancadas em um trecho por onde passam as principais procissões, conferindo a elas o caráter de espetáculo, onde turistas e moradores podem assisti-las de modo mais confortável, além das feiras de artesanato, que ocorrem durante a festividade, que se tornam um atrativo a mais para a atividade turística.

Assim, para o planejamento da atividade turística, considerou-se evidente a necessidade de se analisar as características e expectativas dos diversos agentes do 
processo de turistificação do espaço no Círio de Nazaré, buscando-se, assim, promovêla de modo mais satisfatório à maior parte dos grupos sociais direta ou indiretamente envolvidos.

\section{REFERÊNCIAS}

BARRETTO, M. Turismo e legado cultural. Campinas: Papirus, 2000.

BRASIL. Ministério do Turismo. Turismo Cultural: orientações básicas. 3. ed. Brasília: Ministério do Turismo, 2010.

CASTRO, C. A. T. Processos de patrimonialização e turistificação na produção do espaço do bairro Cidade Velha, Belém-PA. 2012. 109f. Dissertação (Mestrado). Programa de Pós-Graduação em Geografia. Universidade Federal do Pará. Belém, 2012.

CASTRO, C. A. T. ; SERRA, D. R. O. Gastronomia Amazônica e Turismo na Festa do Círio de Nossa Senhora de Nazaré, em Belém do Pará - Brasil. In: CONGRESSO INTERNACIONAL TURISMO, LAZER E CULTURA, 2011, Coimbra. Livro de Resumos do. Coimbra: Faculdade de Letras da Universidade de Coimbra, 2011. v. 1. p. 17-17.

COELHO, M. C. N. Natureza e discurso ecoturístico na Amazônia. Território, Rio de Janeiro, v. 5, p. 67-84, jul./dez. 1998.

CORRÊA, R. L. Espaço: um conceito-chave da Geografia. In: CASTRO, I. E. de; GOMES, P. C. da C.; CORRÊA, R. L. (Orgs.). Geografia: conceitos e temas. 11. ed. Rio de Janeiro: Bertrand Brasil, 2008.

COSTA, F. de A; DINIZ, M. B; FARIAS, A. M. de M.; SOUSA, J. N.; COSTA, J. de A. Círio de Nazaré: economia e fé. Relatório Final. Núcleo de Altos Estudos Amazônicos/UFPA e Instituto de Economia/UFRJ. Belém, s./d. Disponível em: <http://www.agencia.fapesp.br/arquivos/cirio.pdf>. Acesso em: 09/12/2012.

CRUZ, R. C. Política de turismo e território. 2. ed. São Paulo: Contexto, 2001.

Geografias do Turismo: de lugares a pseudo-lugares. São Paulo: Roca, 2007.

FIGUEIREDO, S. L. Círio de Nazaré: festa e paixão. In: FIGUEIREDO, S. L. (Org.). Círio de Nazaré: festa e paixão. Belém: EDUFPA, 2005.

FRATUCCI, A. C. A Dimensão Espacial nas Políticas Públicas Brasileiras de Turismo: as possibilidades das redes regionais de turismo. Tese (Doutorado em Geografia). Niterói: UFF, 2008. 
FRUGOLI, R.; BUENO, M. S. O Círio de Nazaré (Pará, Brasil): relações entre o sagrado e o profano. Turismo e Sociedade. v. 7, n. 1, p. 135-155, jan. 2014.

HAESBAERT, R. O mito da desterritorialização: do "fim dos territórios" à multiterritorialidade. Rio de Janeiro: Bertrand Brasil, 2004.

INSTITUTO DO PATRIMÔNIO HISTÓRICO E ARTÍSTICO NACIONAL - IPHAN, Ministério da Cultura. Círio de Nazaré - Dossiê - Volume I, Belém, 2004.

IVARS, J. A. Planificación turística de los espacios regionales en España. Madrid: Sintesis, 2003.

KNAFOU, R. Turismo e Território: por uma abordagem científica do turismo. In: Rodrigues, A. A. B. Turismo e geografia: reflexões teóricas e enfoques regionais. São Paulo: Ed. Hucitec, 1996.

MATOS, L. da S. Belém em festa: a economia lúdica da fé no Círio de Nazaré. São Paulo: Tese de Doutorado em Ciências Sociais, PUC, 2010.

MELLO, J. B. F. de. Geografia humanística: a perspectiva de experiência vivida e uma crítica radical ao positivismo. In: Revista Brasileira de Geografia, Rio de Janeiro: IBGE, v. 52, n. 4, p. 91-115. 1990.

MORAES, L. A. de; GÂNDARA, J. M. G. Midiatização e espetacularização do turismo. Turismo e Sociedade. Curitiba, v. 9, n. 1, p. 1-18, 2016.

OLIVEIRA, C. D. M. de. Turismo religioso. São Paulo: Ed. Aleph, 2004.

PAES-LUCHIARI, M. T. D. Centros históricos: mercantilização e territorialidades do patrimônio cultural urbano. GEOgraphia, Rio de Janeiro, n. 14, p. 43-58, 2005.

PANTOJA, V. Negócios Sagrados: reciprocidade e mercado no Círio de Nazaré. Dissertação (Mestrado), Universidade Federal do Pará, Centro de Filosofia e Ciências Humanas, Programa de Pós-Graduação em Ciências Sociais, Belém, 2006.

PARÁ. Estudos da Paratur e do Departamento Intersindical de Estatística e Estudos Sócio-Econômicos - DIEESE. Belém. 2010.

Ver-o-Pará: Plano Estratégico de Turismo do Estado do Pará. Belém: Companhia Paraense de Turismo, 2011.

Estudos da Paratur e do Departamento Intersindical de Estatística e Estudos Sócio-Econômicos - DIEESE. Belém. 2012.

Estudos da Setur e do Departamento Intersindical de Estatística e Estudos Sócio-Econômicos - DIEESE. Belém. 2016. 
ROSENDAHL, Z. Geografia da Religião: uma proposição temática. Espaço e Tempo, São Paulo, n. 11, p. 9-19, 2002.

A natureza do espaço: técnica e tempo, razão e emoção. 4. ed. São Paulo: EDUSP, 2006.

SANTOS, Maria. da G. M. P. Espiritualidade, turismo e território. São João do Estoril: Principia. 2006.

SILVA, K. de O. S; FONSECA, M. A. P. da. A geografia e a dimensão espacial do turismo: um ensaio exploratório. Publica, Natal, p. 1-9, 2010.

SOUZA, M. J. L. de. O território: sobre o espaço e poder, autonomia e desenvolvimento. In: CASTRO, I. E. de; GOMES, P. C. da C.; CORRÊA, R. L. (Orgs.). Geografia: conceitos e temas. 11. ed. Rio de Janeiro: Bertrand Brasil, 2003.

Recebido em: 28-06-2017.

Aprovado em: 28-07-2017. 